\title{
Sobre el pensamiento complejo
}

Me llamo Belén Navarro Llobregat, soy trabajadora social y residente en El Ejido (Almería). Desde 2011 escribo en un blog al que llamé trabajo social y tal porque trabajo social y otras hierbas estaba ocupado. Ahora que lo pienso también podría haberlo titulado Mi trabajo social y otros animales, emulando el título del famoso libro de Gerald Durrell, pero igual alguien no se lo hubiera tomado bien. Lo que quiero decir es que necesitaba un título que me permitiese tomarme la libertad de escapar del trabajo social de vez en cuando.

El blog es un monstruo insaciable que pide (o más bien exige) ideas todas las semanas lo que a su vez me obliga a leer mucho, una bendita obligación porque es mi actividad favorita, después de echar la siesta o tomarme unos vinos en buena compañía. A pesar de que leo mucho sobre trabajo social, las mejores ideas para el blog me han llegado de fuera. Suelo leer ensayo (supuestamente) no relacionado con la disciplina y también novela. Digo supuestamente porque estoy convencida de que, tal y como afirma Zamanillo (2018), hemos de salir de lo autorreferencial y aprehender la realidad desde la complejidad. En otras palabras, para crecer como trabajadoras sociales es importante buscar conocimientos en campos disciplinares ajenos para relacionarlos e incorporarlos al trabajo social, además, hemos de entender la complejidad como el paradigma que rige no solo nuestra acción profesional sino la vida misma.

Acorde con el pensamiento de Teresa Zamanillo la otra Teresa, Matus, incorporó en sus tesis el concepto de inteligencia ciega o puntos ciegos, como pudimos escuchar en su conferencia inaugural del XIII Congreso Estatal del Trabajo Social en 2017. La inteligencia ciega es parte del pensamiento complejo al que me quiero referir. Dos preguntas son las que se plantean entonces: ¿Qué es el pensamiento complejo? y ¿Qué tiene que ver el pensamiento complejo con el trabajo social?

\section{1. ¿Qué es el pensamiento complejo?}

Para conocer la respuesta a esta pregunta sería aconsejable acudir a la fuente original, es decir: al libro de Edgar Morin, Introducción al pensamiento complejo, una obra fundamental y determinante para cualquier rama del saber. De modo muy resumido diré, siguiendo a Morin (2007), que para entender el pensamiento complejo hay que partir de la existencia de un paradigma de la simplicidad que entiende el universo en torno a los parámetros orden y desorden, fenómenos antagónicos en los que el orden se entiende como lo deseable y el desorden como lo indeseable, obviando la evidencia de que orden y desorden son fenómenos dinámicos que, además, se retroalimentan. En relación con lo anterior, para entender el orden que regula los fenómenos la ciencia ha tratado de ir desvelando las leyes que los rigen con lo que el conocimiento se ha ido parcelando en diferentes materias inconexas entre sí: La mente es estudiada por la psicología, el cuerpo humano por la biología, etc.

Orden y desorden se entienden desde este paradigma de la simplicidad de una forma disociada: el orden es lo bueno y el desorden es lo malo. Frente a esta manera de entender los fenómenos del universo, Morin afirma que el orden y el desorden son elementos que interaccionan puesto que "fenómenos desordenados son necesarios en ciertas condiciones, en ciertos casos, para la producción de fenómenos organizados" (p. 94). Esta es, a grandes rasgos, la idea central del pensamiento complejo. Los fenómenos, que a primera vista pudieran parecer antagónicos, se relacionan de tal manera que pueden convivir en el mismo sistema, lo que nos lleva a la lógica de la incertidumbre y a las contradicciones que son inherentes a la realidad.

A continuación relacionaré todo esto con el trabajo social, no sin antes acabar esta reflexión teórica describiendo muy brevemente los tres principios del pensamiento complejo: 
1. Principio dialógico: Morin lo ejemplifica con el par orden/desorden: "Orden y desorden son dos enemigos, uno suprime al otro pero, al mismo tiempo, en ciertos casos, colaboran (...). El principio dialógico nos permite mantener la dualidad en el seno de la unidad" (p. 106).

2. Principio de recursividad organizacional: Los procesos son recursivos, es decir, la causa es a su vez efecto: "los individuos producen la sociedad que produce a los individuos: Somos a la vez productos y productores" (p.107).

3. Principio hologramático: Expresa la idea de que no solo la parte está en el todo sino que el todo está en la parte. Un ejemplo son las células de nuestro organismo, pues cada una de ellas contiene toda la cadena de nuestro ADN.

La complejidad, que no complicación, es incertidumbre e implica asumir el "carácter multidimensional de la realidad" (p.100), lo que me lleva al nudo gordiano de la reflexión que pretendo compartir, dirigida a realizar la praxis profesional con esta perspectiva.

\section{2. ¿Qué tiene que ver el pensamiento complejo con el trabajo social?}

Puedo aseverar que la primera sensación que experimentamos al iniciar el ejercicio profesional es la de una equilibrista que camina sobre la cuerda, sin red bajo sus pies. No conozco a ninguna profesional que no haya vivido el malestar de no saber qué hacer con los casos, angustiada por la inexistencia de recetas y protocolos que dicten qué hacer en cada momento; que no haya pedido que la institución ofrezca más recursos, ansiolíticos, en realidad; que no haya dicho que no le han enseñado a intervenir.

Entender la intervención social como una práctica sujeta a recetarios es partir del paradigma del pensamiento simple. Barriga (2009) lo define, dentro de las diez traiciones al trabajo social, como el mecanicismo irreflexivo, en su conferencia El sexto sentido en Trabajo Social, que clausuró el XI Congreso Estatal de Trabajo Social. Animo a la lectura de esta conferencia, especialmente en lo que se refiere a las diez traiciones, y me dispongo a describir otras consecuencias del pensamiento simple, como es el pensamiento disociado: "Si esto es bueno, lo contrario tiene que ser lo malo" (Zamanillo, 2018, p. 155).

Cuando leí el concepto del pensamiento disociado, en el libro que Zamanillo publicó recientemente (precisamente en la editorial de la Universidad Complutense), experimenté cierta sorpresa porque es el origen de una tendencia que yo venía observando en la praxis profesional, a la que no supe darle consistencia teórica (¡claro que yo no soy Teresa Zamanillo!). La autora ilustra la idea del pensamiento disociado con la separación entre intervención y gestión, un par de conceptos en el que la intervención es lo bueno, lo deseable y la gestión es lo malo, lo indeseable:

Los trabajadores sociales (...) están empeñados en marcar una diferencia, inexistente en la práctica, entre intervención y gestión (...). Intervención es todo un proceso que se pone en marcha desde el momento en que (...) solicitan ayuda. La gestión no es más que un momento o varios del proceso (p. 83).

La disociación entre intervención y gestión me retrotrae a varias dialécticas (equivocadas en mi opinión) entre el trabajo de despacho y de calle, entre lo individual y lo comunitario procedentes (sobre todo la primera) del pensamiento simple. El trabajo de calle es la práctica deseable y la atención en despacho su contrario, el lugar del que deberíamos salir a toda velocidad. Esta es una creencia que obvia la evidencia de que ambos lugares cumplen su función y, lo que es más importante, que se pueden realizar praxis emancipadoras en despacho y que, por desgracia, vemos con demasiada frecuencia praxis paternalistas y asistencialistas en el trabajo de calle. Despacho y calle son escenarios necesariamente compatibles.

Relacionado con lo anterior, me maravilla la obsesión no solo de las profesionales sino de muchas autoras provenientes del mundo académico de dotar a la visita domiciliaria de una trascendencia casi mística para el trabajo social. He llegado a leer incluso que "es una técnica privativa de la disciplina del trabajo social" (Quiroz, citado en García y Esteban, 2016, p.177). Sustentar la epistemología del trabajo social con un cimiento como la visita domiciliaria no parece la mejor de las ideas.

En esta línea también hay cierta creencia en la profesión de que lo individual es un nivel del trabajo social asociado con praxis neo-libe- 
rales y lo comunitario es el espacio deseable para la acción transformadora. Es innegable el poder de la comunidad y, sobre todo, de los grupos que en ella se integran, aunque convendremos en que el método básico hizo un buen aporte al unificar los métodos en niveles y conectarlos con teorías emancipadoras como la de Freire; teorías que pueden y deben ser puestas en práctica también en el ámbito individual - familiar. Por otra parte, tampoco es descabellado pensar que ciertas prácticas comunitarias pueden contener elementos de opresión o de mantenimiento del statu quo. Ninguna modalidad de intervención sobre la realidad es inocente y mucho menos neutra.

Otra creencia arraigada en la praxis del trabajo social y de la intervención social en general es que hemos de darle voz a los sin voz. El lenguaje, como sabemos, no es inocente. "Nuestro proceso de pensamiento estructura nuestro lenguaje y el lenguaje estructura nuestro pensamiento y nuestras acciones" (Civit y García, 2018, p.94). La frase-trabalenguas de la voz a los sin voz contiene la premisa de que hay personas que no la tienen. Esta premisa es falsa: todo el mundo tiene voz. Cosa diferente es que haya personas que no tengan la oportunidad de ser escuchadas o, lo que es peor, que se les haya negado esa posibilidad. Como también sabemos, para que las personas o los colectivos puedan ser escuchados es condición indispensable el ejercicio de la participación ciudadana que, a su vez, encierra dos dimensiones: ser parte de algo (pertenecer a) y tomar parte en algo (intervenir y poder decidir). De estas dimensiones dependerá que los sin voz puedan convertirse en ciudadanía activa que pueda tomar el control de su propia vida, elaborar proyectos colectivos y ser escuchados (Alberich y Espadas, 2014).

Como he dicho, hay personas que no tienen posibilidad de ser escuchadas y otras a las que se les ha negado esa posibilidad. Yo trabajo con personas adultas sujetas a medidas de incapacitación legal. Ahora, al amparo de la Convención de Nueva York hacia las personas con discapacidad, lo adecuado es hablar de personas con la capacidad de obrar jurídicamente modificada. En cualquier caso en la práctica se traduce en su incapacidad para tomar ciertas decisiones por lo que, de alguna manera, se les ha robado la voz. Podemos, desde el pensamiento simple, interpretar que si hay una sentencia que impide la toma de decisiones el trabajo de una entidad tutelar consiste en administrar y decidir por su propio bien, sin embargo desde la perspectiva de la complejidad tendremos que articular nuestra labor de una manera diferente, ya que el plano jurídico no debe determinar nuestra intervención profesional. Así, la intervención deberá dirigirse hacia la puesta en marcha de mecanismos para que la persona pueda tener una participación efectiva en la toma de decisiones que afectan a su propia vida porque es lo ético. Y lo más complejo, qué duda cabe.

\section{Algo de literatura a modo de conclusión}

Edgar Morin es solo un ejemplo de lo mucho que otros campos disciplinares pueden aportar al trabajo social. Interpretar la realidad desde el paradigma de la complejidad nos ayuda a entender mejor la sociedad y nos ofrece claves para intervenir mejor. Al principio de esta reflexión citaba a Zamanillo, quien afirmaba que es urgente para el trabajo social salir de lo autorreferencial. Hace poco leí un libro de Chimamanda Ngozi Adichie que me recordó muchísimo las prácticas narrativas de Epston y White. Esta escritora tiene relatos maravillosos, como los que conforman su libro Algo alrededor de tu cuello (Random House, 2015), no obstante a mí me fascinan sus reflexiones, casi más conocidas que su propia producción literaria ¿Quién no ha oído hablar de su famosa charla TED Todos deberíamos ser feministas?

Enganchada como estoy a sus ensayos por llamarlos de alguna manera (porque en realidad son libritos pequeños, transcripciones de sus charlas), leí el último que publicó su editorial, titulado El peligro de la historia única. De ese brevísimo texto me deslumbró este párrafo:

Las historias importan. Importan muchas historias. Las historias se han utilizado para desposeer y calumniar, pero también pueden usarse para facultar y humanizar. Pueden quebrar la dignidad de un pueblo, pero también pueden restaurarla $(2018$, p.28).

De nuevo, el paradigma de la complejidad aplicado a la historia, en este caso, de los pueblos. Al leer este párrafo no pude evitar pensar que las trabajadoras sociales como formuladoras de historias a través de informes y diagnósticos acumulamos mucho poder, un poder que 
si es aplicado en sustantivo puede dañar y si es aplicado como verbo puede reparar, curar, reconocer, validar (Zamanillo, 2018).

La realidad es compleja, los colectivos, grupos y familias también lo son. Un comediante norteamericano, Trevor Noah, cuenta en su libro autobiográfico Prohibido nacer que su madre lo quería tanto que lo tiró de un coche en marcha, y su padre lo quería tanto que cuan- do paseaba con él lo hacía por la vereda de enfrente, sin mirarlo (2017). Para saber por qué invito a adentrarse en este libro, una biografía divertida y a la vez profunda con la Sudáfrica del Apartheid de fondo. También animo a leer a Morin, a Chimamanda, a...

Belén Navarro Llobregat bnavarrollobre@gmail.com

\section{Referencias bibliográficas}

Alberich, T. y Espadas, M.A. (2014, junio). Democracia, participación ciudadana y funciones del trabajo social. Trabajo social global, Revista de Investigaciones en Intervención Social, 4( 6), 3-30. Disponible en: http://hdl.handle.net/10481/33978

Barriga, L. (2009, mayo, 6-8). El sexto sentido en trabajo social. Alegoría de la construcción del relato en Trabajo Social. XI Congreso de Trabajo Social, Zaragoza.

Civit, M. y García, M. (2018, abril). El trabajo social, en femenino, y su relación con el poder. Revista de Treball Social. Col-legi Oficial de Treball Social de Catalunya, 212, 83-94. Disponible en: https:// dialnet.unirioja.es/servlet/articulo? codigo $=6641377$

García-Longoria, M.P. y Esteban, R.M. (2016). Análisis y diagnóstico en trabajo social. Valencia: Tirant lo Blanch.

Matus, T. (2017). Ejercicios de punto ciego. Desafíos de innovación y gestión de calidad en los procesos de intervención social. En: Ana Lima, Enrique Pastor y Carmen Verde (coord.). El trabajo social: construyendo comunidades sostenibles (pp. 45-79). Cizur Menor: Aranzadi.

Morin, E. (2007). Introducción al pensamiento complejo. Barcelona: Gedisa.

Ngozi, C. (2018). El peligro de la historia única. Barcelona: Penguin Random House.

Noah, T. (2017). Prohibido nacer. Barcelona: Blackie Books.

Zamanillo, T. (2018). Epistemología del trabajo social: De la evidencia práctica a la exigencia teórica. Madrid: Ediciones Complutense. 